\title{
Decision Support System for Selecting Students to Follow Biological Science Olympiad Using Simple Multi Attribute Rating Technique (SMART) Method
}

\author{
Basrie* \\ Information System, STMIK Widya Cipta Dharma, \\ Samarinda, 75123, Indonesia \\ basrie@wicida.ac.id \\ *Corresponding author
}

\author{
Ekawati Yulsilviana \\ Informatics Management, STMIK Widya Cipta \\ Dharma, Samarinda, 75123, Indonesia \\ ekawati@wicida.ac.id
}

\begin{abstract}
'Abstract- Decision Support System (DSS) is a system that can help someone in making decisions that are accurate and right on target. many problems can be solved by using DSS, one of which is the Decision Support System for Student Selection to Participate in the Biology Science Olympiad with Method (Simple Multi-Attribute Rating Technique). The purpose of this research is to produce a Decision Support System for Student Selection to Participate in the Biology Science Olympiad with the Method (Simple Multi-Attribute Rating Technique), with the hope of selecting students to objectively participate in the National Science Olympiad. By using the Visual Basic.Net programming language and the database used is MySql. In this research, data collection techniques used are observation library studies and interviews. The results of this study are made a decision support system to participate in the Biology Science Olympiad with the Method (Simple Multi-Attribute Rating Technique) after the decision is obtained, the system will display the decision.
\end{abstract}

Keywords - Decision Support System, Biology Science Olympiad, Simple Multi-Attribute Rating Technique

\section{INTRODUCTION}

The mastery of science and technology is one of the main requirements for the progress of a nation. The Directorate of High School Development, the Directorate General of Primary and Secondary Education, the Ministry of Education and Culture has made various efforts in the context of developing the talents and interests of high school students in science and technology. These efforts were carried out through the National Science Olympiad (OSN).

National Science Olympiad (OSN) is expected to lead students to master science and technology, this Olympics is also an important part in the distribution of achievements and maximizing the potential of talented and character students.

So to simplify the selection process in selecting the Biology Science Olympiad group at SMA Negeri 5 Samarinda, a computer-based Decision Support System (DSS) needs to be built. This system is a computer-based system that is intended to assist in decision making and analytical skills in group selection.

Biology Science Olympiad by utilizing certain data and models to solve various problems. The decision making process is carried out using the Simple Multi Attribute Rating Technique (SMART) method, which is one of the methods used to complete the decision making system by considering criteria and weights.

Legal Basis

1. Law Number 29 of 2003 concerning the National Education System.

2. Presidential Regulation Number 87 Year 2017 Regarding Strengthening Character Education.

3. Government Regulation Number 17 of 2010 concerning Management and Organization of Education.

4. Regulation of the Minister of National Education Number 34 Year 2006 concerning Fostering the Achievement of Students with Special Potential and / or Devotion.

5. Minister of National Education Regulation No. 19 of 2007 concerning Education Management Standards and Elementary and Secondary Education Units.

6. Minister of Education and Culture Regulation Number 39 Year 2008 Concerning Student Development.

7. Minister of Education and Culture Regulation No. 62 of 2014 concerning Extracurricular Activities in Primary and Secondary Education

8. Regulation of the Minister of Education and Culture No. 63 of 2014 concerning Scouting Education as a Compulsory Extracurricular.

9. Minister of Education and Culture Regulation Number 18 Year 2016 Regarding Introduction to the School Environment for New Students.

10. Minister of Education and Culture Regulation Number 82 Year 2015 Prevention and Management of Violence in the Educational Unit Environment.

11. Regulation of the Minister of Education and Culture Number 23 Year 2015 Regarding Growth of Character. 
12. Ministry of Education and Culture Strategic Plan 2015-2019; and

13. DIPA (Budget Implementation Entry List) 2018 High School Education Provision and Service Program.

\section{LITERATURE REVIEW}

According to Sutabri (2012), the system is a form of integration between one other Components because the system has different targets for each case that occurs in the system. Therefore, the system can be classified from several viewpoints, such as examples of systems that are open and closed systems.

According to Hutahaean (2014), the system is a network of interrelated procedures, gathered together to carry out activities or to carry out certain targets. The characteristics of a system so that the system is said to be a good system are as follows:

1. Component

A system consists of components that interact with each other which means work together to form one unit. System components consist of components in the form of subsystems or parts of the system.

2. System Limits (Boundary)

System boundary is an area that limits between a system with other systems or with the environment outside. These system limits allow a system to be seen as a single unit. Limitation of a system shows the scope (scope) of the system.

3. External Environment System (Environment)

Environment outside the system (environment) is outside the boundaries of the system that affect system operation. The environment can be beneficial which must be maintained and the harm must be maintained and controlled if it will not interfere with the survival of the system.

4. Interface System

The connecting system is a media liaison between subsystems with other subsystems. Through this link allows resources to flow from one subsystem to another subsystem. The output (output) of the subsystem will be input (input) to other subsystems through the connector

5. Enter System (Input)

Enter the system is the energy put into the system, which can be in the form of maintenance (maintenance input) and enter the signal (signal input). Maintenance input is the energy put into the system to operate. Signal input is the energy processed to obtain output.

6. System Output (Output)

The system output is the result of energy that is processed and clarified into useful output and residual disposal.

\section{System Processor}

A system is a part of the processor that will convert inputs into outputs. The production system will process raw materials into finished materials; the accounting system will process data into financial reports.

8. System Target
A system must have a goal (goal) or target (objective). The goal of the system is to determine the input needed by the system and the output that the system will produce.

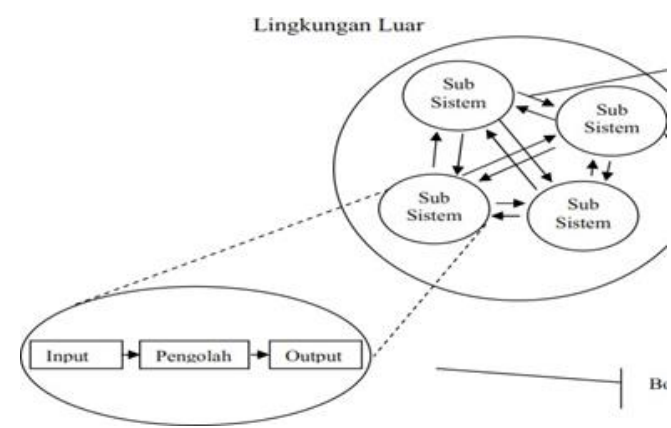

Picture. 1 Characteristics of a Source System: Hutahaean (2014). (Concept of Information Systems)

Based on the opinions of the experts above about the system, it can be concluded that the system is an interconnected elements and interact with others in one entity to achieve a certain goal.

\section{A. Decision Support System}

According to Pratiwi (2016), a decision support system is a computer-based information system that produces various alternative decisions to assist management in dealing with various structured or unstructured problems using data or models. Decision support systems utilize the resources of individuals with computer capabilities to improve the quality of decisions. So, this computer-based decision support system can be used for management decision making related to semistructured problems. Decision Support System (DSS) or supported by a Decision Support System supported by a computer-based information system can help someone improve their performance in decision making.

\section{B. Decision}

According to Pratiwi (2016), the decision making process is something that will always be faced by humans. The decision taken is usually because there are certain considerations or logical basis, there are the best alternatives from the several alternatives that must be chosen and the objectives to be achieved. Decisions are the result of thinking in the form of a choice among several alternatives that can be used to solve the problem at hand. Decision making is carried out by the leader to solve the problems encountered in the organization he leads by selecting an alternative consideration of certain criteria. Decision making must be done systematically, gathering facts, then there is a mature determination of the alternatives faced and then take the action that according to the calculation is the most appropriate action. The types of decisions can be divided into 3 (three) types of decisions which include:

\section{Structured Decisions}

Decisions related to previously known issues. The decision-making process as usual is based on certain techniques and standards have been made. This category 
of decision can also be regarded as an automatic response process to predetermined policies. Naturally almost all routine and recurring problems have parameters of problems that are well known and well-defined, so that answers or decision-making processes are routine and scheduled.

2. Unstructured Decisions

Decisions related to new issues. Unstructured decisions are usually related to fairly complex issues, because the parameters are unknown or not yet known. Therefore, to take this decision usually intuition and experience of an organization's actors will be very helpful. 3. Semi-structured Decisions

There are some structured decisions, but not all of the phases. Semi structured decisions are characterized by incomplete rules for making decisions and the need to make judgments and subjective considerations as a complement to formal data analysis.

Based on the opinions of the experts above about the decision, it can be concluded that the decision is a result of solving the problem that has been faced

\section{Simple Multi Attribute Rating Technique (SMART) Method}

According to Pratiwi (2016), Simple Multi Attribute Rating Technique (SMART) is a multi-attribute technique or method in decision making systems. This method was developed in 1977 by Edward. The decision maker must have different objects and have the same opportunity, adjusted to the goals that have been formulated. Each of these objects has characters, components, or criteria in the decision. But in a condition does not rule out the possibility of sub-criteria related to existing criteria. The characters, components or criteria of this decision have values. This value is averaged on a certain scale. Each criterion has a weight that defines how important the criterion is more important than the other criteria. This

weighting is done to assess each different object that have the same opportunity, so getting the best object. Weighting at SMART uses a scale between 0 and 1, making it easier to calculate and compare values for each alternative. The models used in the SMART (Simple Multi Attribute Rating Technique) are:

$$
(a i)=\sum \underset{j=1}{m} u i(a i)=1,2, \ldots m(1)
$$

Information:

$w j=$ weighting value of the jth criteria and $\mathrm{k}$ criteria $\mathrm{u}$ (ai) $=$ value of the utility of the th criteria for the $\mathrm{i}$ criteria for decision selection is to identify which of the $n$ alternatives has the greatest function value.

\section{Steps Using Smart Techniques}

Step 1: determine the number of criteria

Step 2: The system defaults to a scale of 0-100 based on the priorities that have been set input then normalized.

The normalization formula is $=: \mathrm{N}=\square \square$

Note: $w j$ : the weight of a criterion
Step 3: provide criteria values for each alternative. Step 4: calculate the utility value for each criterion.

$$
(a i)=\sum w j u i \underset{j=1}{m}(a i)=1,2, \ldots m
$$

Step 5: calculate the final value of each.

$(\square)$ : 1st criterion utility value for the first criterion

.$\square$ : maximum criterion value

.$\square$ : minimal criterion value

Co: i-th criterion value

\section{RESEARCH AND METHODS}

A. Flow chart

According to Indrajani (2014), a flowchart is a graphical depiction of the steps and sequence of procedures of a program. Usually makes it easier to solve problems that need to be further studied and evaluated.

Flow chart is a specific depiction of a chart that shows the flow (flow) in a program or system procedure logically. The program flow section is created using the following symbols:

Table 1. Flowchart Symbols

\begin{tabular}{|c|c|}
\hline Simbol & Keterangan \\
\hline & Simbol titik terminal \\
\hline & Simbol proses \\
\hline & $\begin{array}{c}\text { Simbol input atau output yang } \\
\text { memilki data input atau ouput }\end{array}$ \\
\hline & $\begin{array}{c}\text { Simbol penghubung dimana } \\
\text { menunjulkkan sambungan }\end{array}$ \\
\hline & $\begin{array}{c}\text { Simbol garis alir utuk } \\
\text { menunjukkan arus dari suatu } \\
\text { proses }\end{array}$ \\
\hline & $\begin{array}{c}\text { Digunakan untuk memberikan } \\
\text { milai awal suatu besaran }\end{array}$ \\
\hline
\end{tabular}




\section{B. Flowchart Calculations Using the SMART Method}

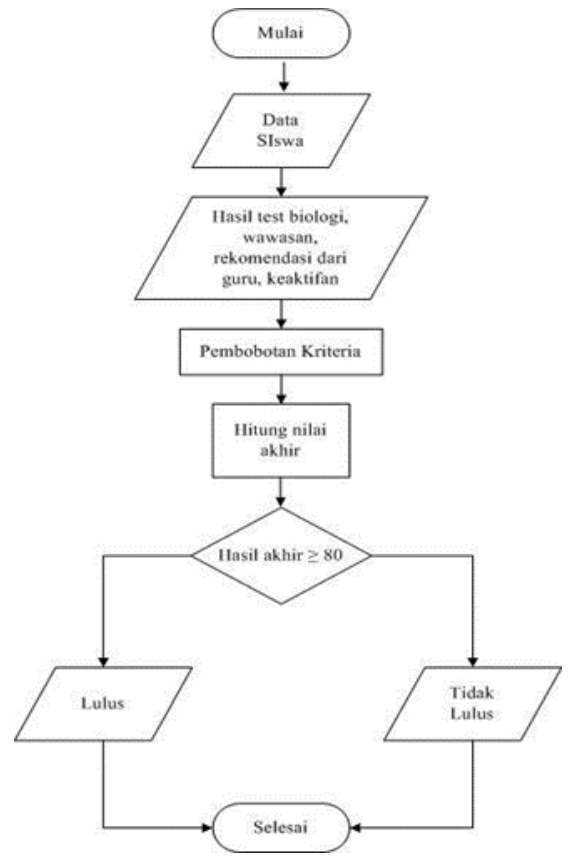

Picture 2. Flow chart Calculation of the SMART Method

This flowchart starts from entering data on selection test results, insights, recommendations from biology teachers, and activeness. Then the criteria will be weighted and normalized. From the normalization process, the results will be seen if greater than or equal to 80 , the students are declared to graduate. And if the score is less than 80 then the students are declared not passed.

\section{System Flowchart Using the SMART Method}

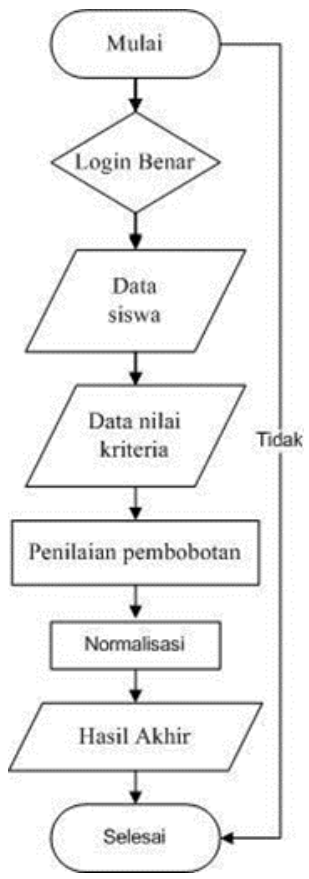

Picture. 3 System Flowcharts Using the SMART Method

Flow chart The system uses the SMART method, starts with the correct login, if the login is incorrect then the program will display a notification of the wrong user name and password, if correct then enter the admin page, input student data, then input criteria and weights, then input sub criteria values, then Process weighting assessment and normalization. After that the system will provide the final results of calculations performed by the system.

\section{RESULT AND DISCUSSION}

1. Display Login Form

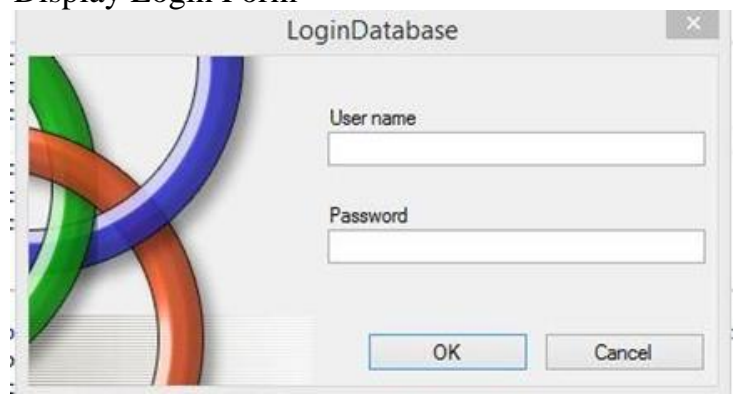

Picture. 4 Login Form

The system will automatically ask for a username and password. If the username and password you entered are incorrect, it will give the message username and password is incorrect.

\section{Form Main course}

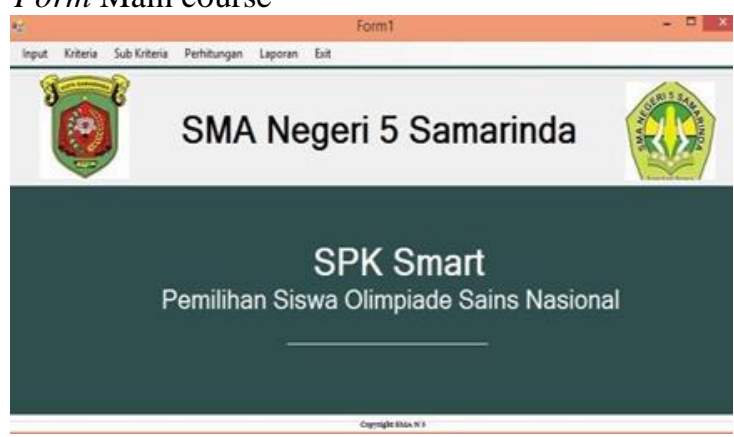

Picture. 5. Main Menu Form

3. Form Criteria

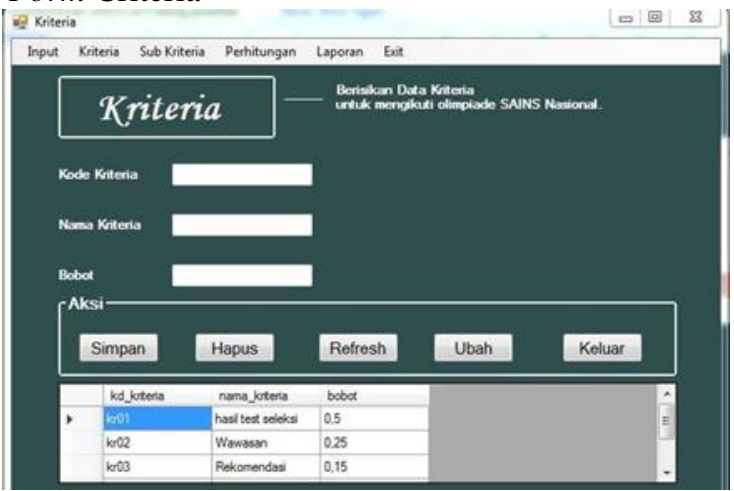

Picture 6. Criteria Form

The criteria form contains the criteria data and sub criteria data. To add criteria please type the criteria code. After filling in the code, then fill in the name of the criteria and the weight of the new criteria, then press the save button. if the Refresh button is pressed then the display will be blank, and can fill in the next criteria code. 


\section{Form Calculation}

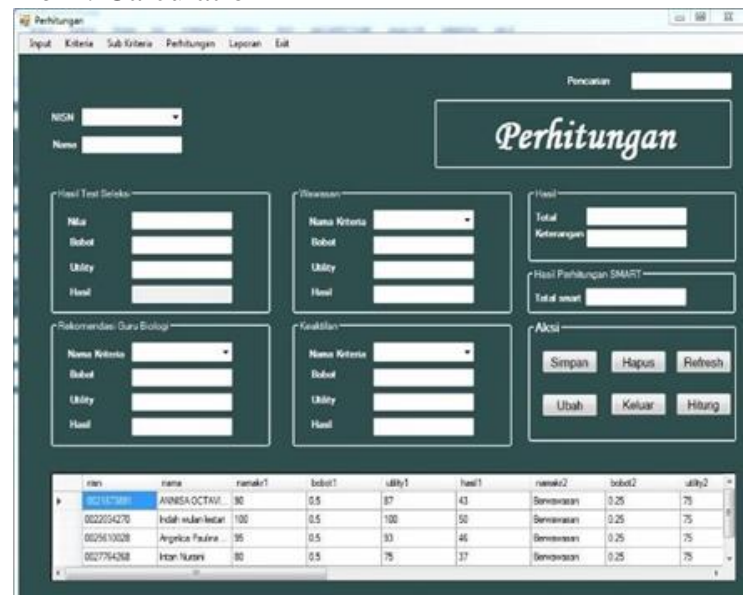

Picture. 7 Calculation Form

In Picture 7 the calculation contains the criterion data If you want to pay attention to students, you must call the data first, choose NISN first, then click on the search button to recall student data, when one of the students has done it again, it will happen. Duplicate data that causes display error. Then the student data has never done a calculation, and then each criterion must be entered so that the total is known and the information passed or did not pass the calculation. Then after the student data and criteria have been entered correctly please click the save button to save into the database.

\section{CONCLUSION}

This system was created using the Visual Basic.Net programming language using the MySQL database. The system used is standalone using one computer as its operation, this system has 4 criteria used, which are the criteria for selection test results, insights, biology teacher's recommendations, and activeness. This system produces a decision support system software for the selection of students to take the Biology Science Olympiad using the SMART (Simple Multi Attribute Technique) method, in testing this system uses two types of white box testing and black box testing. With the decision support system for student selection following the Biology Science Olympiad using the SMART (Simple Multi Attribute Technique) method, it can help biology teachers in making the right decision in determining students, which can be accepted in accordance with predetermined criteria. This system was made to make it easier for biology teachers to make student selection decisions for the Biology Science Olympiad that passed and did not pass, according to the SMART calculation.

\section{REFERENCE}

Bukhari Ahmad. 2016. Supporting System for Radio Broadcaster Acceptance Decisions Using the SMART (Simple Multi attribute Rating Technique) Method.

Hidayatullah, Priyanto. 2012, Visual Basic .NET Creating Database Applications and Creative Programs. Bandung: Informatics.

Hutahaean, Jeperson. 2014, Concepts of Information Systems. Yogyakarta: Deepublish Publisher.

Halim Abdul, 2016, Application of the SMART (SMART (Simple Multi-Attribute Rating Technique) Method in Decision Support Systems Determining the Project Tender Winner in the Medan City Public Works Department of Science and Technology, Informatics Engineering, Medan, Universits Sanata Dharma.

Indrajani.2014. Introduction to the All In One Case Study Database System. Jakarta: Elexmedia Komputindo.

Ichwan, M. 2011. Delphi 7 \& Mysql Database Programming. Bandung: Informatics.

Novianti Dwi, 2016, Web-Based Decision Support System for Cafe Selection Using the SMART (Simple Multi-Attribute Rating Technique) Method, Proceedings of the Science and Technology seminar at FMIPA Unmul, Samarinda.

Pratiwi, Heny. 2016, Textbook of Decision Support Systems. Yogyakarta: Deepublish Publisher.

Pressman, Roger S. 2010, Approach to Software Engineering 7. Yogyakarta: Andi Offset.

Rosa and Saladin. 2015, Structured and Object-Oriented Software Engineering. Bandung: Informatics.

Rusmawan, Uus. 2014, Collection of VB Programs. NET for Final Project and Thesis (Revised Edition). Jakarta: PT. Elex Media Komputindo.

Sutabri, Tata, 2012, Information Systems Analysis. Yogyakarta: Andi Publisher. 